Afr. J. Trad. CAM (2006) 3 (1): 11 - 22

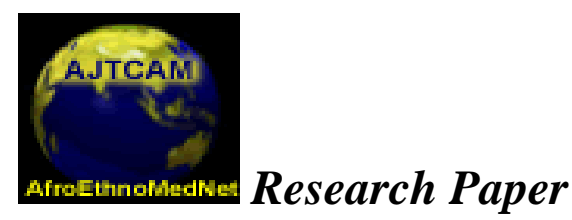

ISSN 0189-6016@2006

\author{
Afr. J. Traditional, \\ Complementary and \\ Alternative Medicines \\ www.africanethnomedicines.net
}

\title{
TRADITIONAL MEDICINE IN LATE PREGNANCY AND LABOUR: PERCEPTIONS OF KGABA REMEDIES AMONGST THE TSWANA IN SOUTH AFRICA
}

\author{
${ }^{1}$ Rolanda van der Kooi (primary researcher), ${ }^{2}$ Sally Theobald (supervisor), \\ ${ }^{2}$ Liverpool School of Tropical Medicine, Pembroke Place, Liverpool, L3 5QA, UK, \\ ${ }^{1}$ Liverpool School of Tropical Medicine,UK; The REACH Trust, \\ P.O. Box 1597, Lilongwe, Malawi \\ E-mail: ${ }^{1}$ vrolanda@zonnet.nl, tel: + 31 (0) 20 4123111, ${ }^{2}$ sjt@liv.ac.uk, tel: +265 (0) 9335760, \\ fax: +265 (0)1751247
}

\begin{abstract}
In South Africa most black women use antenatal care services and deliver in clinics, and a considerable number complement this use of formal health services with traditional medicine. This study reported here examined the knowledge, beliefs and practical experiences of pregnant women, traditional healers and midwives with regard to kgaba (traditional medicine) and explored what constitutes kgaba. Interviews $(\mathrm{N}=30)$ and focus group discussions $(\mathrm{N}=21)$ were carried out among participants in Mogwase district in the North West Province of South Africa, where the use of kgaba remedies is commonly believed to cause foetal distress and an increase in caesarean sections. Findings indicated that kgaba remedies are ingested not only to prevent or solve physical problems but are also perceived as valuable in protecting against the harm that evil spirits can cause during pregnancy. Experiences with kgaba differed among participants and this may relate to the variety of plants used, their preparation and dosage. The use of crushed ostrich eggshell, which is perceived as inducing labour, emerged as an important finding. The use of kgaba as perceived by the Tswana is an important component in the experience of pregnancy and labour. However, communication about the use of kgaba between pregnant women and health staff was poor and hinders reporting or recording of dosage and evaluation of effects. There is a need to develop strategies that promote open dialogue between health providers and communities on the use of traditional medicine.
\end{abstract}

Key words: traditional medicine, labour, ethnopharmacology, South Africa

\section{Terms used}

In this study the term traditional medicine (TM) is used for medicines of plant, animal or mineral origin, which are taken orally. The definition of tradition healer $(\mathrm{TH})$ includes both diviners, who use bone throwing for diagnosis, and herbalists. Nowadays the distinction between these two healers is not always clear and they may be combined. 
Afr. J. Trad. CAM (2006) 3 (1): 11 - 22

\section{Introduction}

\section{Modern and traditional health systems: complementary or contradictory?}

In developed countries, communities and midwives are showing a renewed interest in the use of herbal and alternative medicine (Belew, 1999). In the African context, traditional medicine (TM) in pregnancy and labour continues to play, as it did in the past, an important role in health systems. Western oriented medicine and health systems, introduced during the colonial era, did not eliminate well established systems of TM and many Africans learnt to use both health systems depending on the availability of medicine or the nature of the illness (Freeman and Motsei,1992). Both systems derive their theories of illness from the beliefs, values, and interpersonal relations of the society from which they evolved (Chipfakacha, 1994). This in turn shapes the strategies and behaviours that community members develop in coping with illness and seeking health care, and whether their first choice will be self-treatment, traditional medicine or biomedicine (Good, 1987).

The main difference between African TM and Western biomedicine is the way in which health and illness are conceptualised. Illness in TM implies a social, spiritual and physical imbalance that requires a natural remedy. Additionally, traditional healers try to explain who or what caused the disease and why this person is affected at that particular time (HST, 1999).

Magical or supernatural forces and rituals often guide this process, and herbal knowledge can also bring about harm (usually seen as witchcraft) (Haram, 1991). This is reflected in language, and the Tswana word Dikgaba means harm or heartache others can cause (Ulin, 1979). These supernatural elements probably underscore the suspicion many biomedical staff have towards TM and their reluctance to recognise and work with it even when from the same cultural belief system (Barbee, 1986).

\section{Policies}

At the international level the discussion of co-operation focused first on incorporation of traditional healers (THs) in Primary Health Care. However, it has been increasingly questioned whether western biomedicine and TM can operate in a complementary way without one changing or oppressing the other (Feierman, 1986). Nowadays the discussion concentrates more on integration through regulation (associations, licences and training), research and investments in effective services, products and consumer information (Bodecker, 2001 and WHO, 2002). The government of South Africa supports these developments, although realising them in practice is no easy task. Estimates of traditional medical practitioners in South Africa are between 150.000 and 350.000, while the number of biomedical doctors is around 25.000 (Kale, 1995). Legislation is delayed and collaboration on equal footing is still far from being achieved (HST, 1999). This is seen by some as showing a lack of real commitment from the government and evidence of discrimination against black Africans (Thomson, 2001). Only recently South Africa's Department of Health founded the Institute for African Traditional Medicines, which will evaluate TM and develop agents for chronic diseases and AIDS, while protecting the intellectual property rights of THs who generate herbs for testing (BuaNews, 2003).

\section{Traditional Medicine in pregnancy and labour in South Africa}

Health seeking behaviour amongst pregnant women in South Africa is different from that in most other Sub Saharan countries. In the 1960's most South African women from all ethnic 
Afr. J. Trad. CAM (2006) 3 (1): 11 - 22

backgrounds gave birth in clinics, and by 1989 South African women were more likely than any other group of women in the world to deliver by caesarean section (Burns, 2001). As a consequence more than $80 \%$ of pregnant women deliver with medical assistance (HST, 2002). In addition, it is estimated that $60 \%$ of South African women use TM during pregnancy (Jewkes et al, 1998a). In South Africa the use of herbal medicines by women in the reproductive age group is common. They are used for abortion, breast cancer, contraception, irregular or painful menstruation and conception (Steenkamp, 2003). In pregnancy herbs are normally used orally on a regular basis as a tonic to clean the womb (Varga and Veale, 1997), to attain an easy and quick delivery (Gumede, 1978), and in order to protect the child from evil and to have a healthy child (Gonçalves, 2001). Other factors underlying the use of traditional medicine have been identified as social pressure, dissatisfaction with the behaviour of clinic staff, reluctance of clinic staff to give drugs and lack of privacy within the clinic environment (Jewkes et al.,1998b and Abrahams et al., 2002). To induce labour or stimulate contractions in prolonged labour, several herbs are available and the therapeutic effects of several South African plants have been tested (Kaido et al., 1997 and Varga and Veale, 1997). However some studies, especially among the Zulu and Xhosa populations of South Africa, revealed harmful effects and complications during labour (Mabina et al. 1997 and Varga and Veale, 1997). The kgaba remedy the Tswana use is based on a mixture of plants and minerals that can vary among THs and has not been officially documented.

\section{Ethnopharmacological research}

Toxicity of plants in South Africa has been long documented (Watt and BreyerBrandwijck, 1968) and discussed (Joubert and Sebata, 1982). Dangerous effects investigated in labour are mainly distress of the foetus (Mabina et al., 1997) and an increase in interventions, such as caesarean sections (Varga and Veale, 1997 and Gonçalves, 2001). Many causes may lie behind the adverse effects of herbal medicine: i.e. picking the wrong plant, use of adulterants, incorrect dosage, individual reaction, climate, contamination by micro-organisms, and mistakes in plant part used and preparation (Drew and Myers, 1997). All these variables show that, as with allopathic medicine, research is necessary in traditional medicine, not only for safety reasons, but also for more evidence on the benefits or effectiveness of herbs (Hutchings and Terblanche, 1997), and their cultural value (Etkin, 1988).

In Mogwase district in the north west of South Africa obstetricians' and midwives' observations suggest negative health outcomes amongst Tswana people due to the use of kgaba. The regional Mogwase district manager requested investigations to give clear evidence of the effects of the medicine involved. This request formed the basis for this research. In line with Etkin's (1988) suggestion that modern ethnopharmacological research should focus on the meaning or value a cultural group gives to medicine and efficacy, it was decided that this research should take a broader perspective. Hence this research explores health staff, traditional healers and Tswana women's perceptions of and experiences with kgaba. It also examines the difficulties in identifying the botanical nature of $k g a b a$.

\section{Materials and Methods Study setting}

The Tswana population lives mainly in the North West province of South Africa and in neighbouring Botswana. In Mogwase district the Tswana constitute 98\% of the total population. 
Afr. J. Trad. CAM (2006) 3 (1): 11 - 22

Mogwase district has 45 clinics and 6 health centres, which employ nurses and midwives to offer comprehensive care including antenatal care. Deliveries are carried out in all health centres and some clinics. Several clinics have doctors or medical students providing medical care on an irregular basis. There is one hospital in the district that serves as a referral hospital for complicated maternity cases. The total number of traditional healers in the district and their specialities are unknown. Some co-operation between the formal health sector and traditional healers exists in the development of strategies to raise awareness about HIV/AIDS and to treat tuberculosis patients.

\section{Study design}

This is a qualitative descriptive study. Qualitative methods were chosen as they have great value in sensitively exploring perceptions and understanding different cultural contexts. As data on the use of kgaba were not available the researchers felt it was more feasible and appropriate to first expand the knowledge base of kgaba. To gain insight into the beliefs, norms and practices shaping the use of kgaba the study employed qualitative interviews and focus group discussions (Kitzinger, 1995).

\section{Objectives and methods}

The study, conducted in 2003, aimed to explore and describe:

1) Knowledge, beliefs and practical experiences of pregnant women, traditional healers and health professionals with regard to kgaba

2) The nature of kgaba ingested by the Tswana in late pregnancy and labour.

Focus group discussions $(\mathrm{N}=21)$ with separate groups of pregnant women or new mothers, THs and midwives in 16 different rural locations were conducted. As group interviews may also deter others to speak freely about a sensitive topic semi structured interviews with the same participant groups $(\mathrm{N}=27)$ were conducted to explore opinions not easily shared in groups (Britten, 1995). Additionally, semi-structured interviews with a senior clinician, three medical students and a health promoter were carried out. For practical reasons (time and distance) most interviews were conducted in the clinics. This meant that the research could have been perceived as linked with a clinical, bio medical environment. As a consequence extra emphasis was given to confidentiality, although unfortunately two THs remained very reluctant to participate.

During focus groups and interviews pregnant women or new mothers were asked what kind of TM they used in late pregnancy or labour, the reason for this choice and their experiences with the particular TM. The interactions with midwives focused on their observations and experiences with the use of TM in deliveries in the clinics. THs were asked about their experiences and views too. Additionally, they were approached to learn about the second factor, the nature of the medicine prescribed in late pregnancy and the related problems.

Interviews and discussions were taped, translated where necessary, and transcribed. Themes taken from the topic guides and emerging from the interviews were combined, compared and triangulated in a framework approach that facilitated a thematic content analysis per participant group or location (Ritchie and Lewis, 2003). Data collected on the (botanical) nature of the TM were collated and compared with available information at the Herbarium in Pretoria. The study received ethical approval from the internationally recognised ethics committee at the Liverpool School of Tropical Medicine, United Kingdom and was conducted in an ethically appropriate sensitive manner; informed consent was sought at all times. 
Afr. J. Trad. CAM (2006) 3 (1): 11 - 22

\section{Results}

\section{Concept of $\mathrm{kgaba}$}

The meaning participants gave to kgaba is complex and fluid. Firstly kgaba was seen as a social problem between a pregnant woman and a relative or ancestor who disagreed with her behaviour and could cause harm in pregnancy. This was often regarded as witchcraft. Secondly, most physical problems encountered in pregnancy or labour were also labelled as a $\mathrm{kgaba}$ problem. These social and physical conditions needed protection from harm or treatment with kgaba medicines, the third meaning. The TH was perceived to be the only person who can explain the cause and prescribe medicines based on plants, minerals or animal substances.

The social importance of kgaba was strongly expressed, for example:

'Sometimes a person can bewitch you, or the baby, to die. So if you take kgaba then it won't happen.'

(Interview pregnant woman)

'They can say: "the mother in law doesn't want me and they are going to make me have an abortion or a still birth".'

(Midwife in focus group)

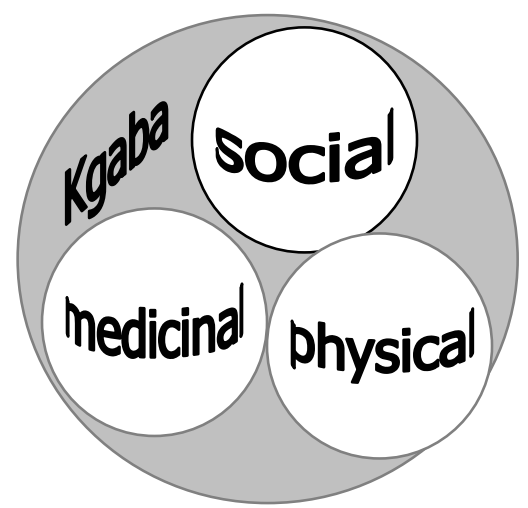

Figure 1: Three fold concept of kgaba.

The physical problem most commonly mentioned was pains in the waist, for which clinics offer no medicine and $\mathrm{kgaba}$ is perceived as the solution. However, one midwife explained that kgaba was used for a wide range of physical problems:

'If you pass the expected date of delivery that means kgaba, if you have prolonged labour that means it is kgaba, if you have pains during pregnancy that means kgaba.'

(Interview midwife)

According to all the participants Kgaba as medicines were most commonly ingested in the third trimester of a pregnancy. At this stage pregnant women take kgaba to prevent and solve difficulties and stimulate a smooth delivery. TM are usually prescribed by a TH or bought in herbal shops. One of the plants used for kgaba is called Kgaba etona and is possibly the source of the name kgaba. 
Afr. J. Trad. CAM (2006) 3 (1): 11 - 22

\section{Nature of $k g a b a$}

18 different plants were identified by THs for kgaba problems and referred to as kgaba. Botanical identification of the plants was hampered by the absence of fresh plants in the research period and the difficulties in combining local names with botanical names. However, several TH's recognised the Rhoicissus Tridentata (Vitaceae family) as the locally named Kgaba etona from pictures in a book of Van Wijk et al.,1997. The Rhoicissus Tridentata / Kgaba etona is one of the ingredients of a decoction Zulu women drink in pregnancy (Varga and Veale, 1997). This plant appears to have an uterotonic effect (stimulating the uterine muscles to contract) (Veale et al., 1998) as well as an effect on the nervous system (Steenkamp, 2003).

An important finding was the frequently used ostrich eggshell to stimulate labour, a mineral of which the pharmacological properties are unknown. Most participants had heard of it and it was a medicine commonly used by women and THs. Other items used are baboon urine and mud of the wasp (a mix of sand and eggs of insects sticking to the walls of a house), or mixtures of these with plants. In churches the ashes of burnt herbs are used with blessed water.

\section{Reasons to use $k g a b a$}

Apart from the use of kgaba to protect from evil and harm, two other important reasons were to stimulate prolonged labour and to induce labour when overdue. Several THs stressed the importance of using kgaba only when they were sure the woman is in labour, and some others said to avoid the use of ostrich egg while in labour

'Ostrich egg is not good if a woman is in labour...it makes the pains to be faster and sometimes the womb can rupture.'

(TH in focus group)

The analysis revealed that being overdue was seen as common in most clinics. Two midwives pointed out that the use of injectable contraceptives and late booking hinders estimation of the delivery date. One midwife, however, suggested that women were reluctant to discuss due dates for fear of witchcraft by others. Only some women emphasised a quick, less painful delivery as their principal motive for using TM. Remarkably, several young women took kgaba but 'did not ask why'. Many participants illustrate, however, other influential factors and persons:

'They say it is our tradition, so I just drink.'

(Woman in focus group)

'... [Granny] says it must be done like that in Tswana, it's tradition.'

(Interview woman)

All participants agreed that usually the grandmothers or mothers make the decision on ingesting kgaba, although a more practical reason for the involvement of others was also given:

' Some are in a lot of pain and cannot think straight!'

(TH in focus group)

Especially where mothers in law are involved, refusal would be difficult as it would show disrespect or:

' ... she will be told that the after effects of you refusing to take that treatment or whatever, you will bear the consequences, either a difficult labour or a still born or whatever, there are so many things...'

(Interview midwife) 
Afr. J. Trad. CAM (2006) 3 (1): 11 - 22

Many religious women said their church forbids them to use TM. Several other churches favour TM or would give herbal teas. There was a minority group of women who said they made their own decision about whether to use kgaba. These were either midwives who had seen the negative outcomes of kgaba during their work, or pregnant women who had heard about $\mathrm{kgaba}$ related problems from others and who already rarely used TM.

Finally, THs made their decisions on the use of kgaba through their knowledge, training and experience. Many are said to acquire their knowledge from visions or ancestors, where the latter guide diagnosis and choice of treatment while throwing and reading the bones. Diviners used bones for diagnosis, treatment choice and explanation of the cause of the ailment. The position of each specific bone towards the others, whether it landed upwards or downwards and the direction in which it points are explained and interpreted by the $\mathrm{TH}$.

' I don't give medication before I examine with the bones, they will tell me if there is a problem.'

(Interview TH)

\section{Effects of $k g a b a$}

The effects of kgaba medicines, especially ostrich eggshell, observed or experienced in labour were diverse among the different participant groups and locations. Staff from the referral hospital revealed that TM can lead to strong, continuous contractions not corresponding to the slow dilation of the cervix. As a result this can cause acidosis in the body of the mother (a metabolic condition that causes the blood to become more acidic that is potentially fatal if not treated) followed by foetal distress and may need intervention by caesarean section or vacuum extraction. Occasionally staff even observed uterus rupture or death. Statistics concerning the use of kgaba were not available making it difficult to ascertain any certain links between the use of kgaba and labour outcomes.

In the clinics few complications were seen although midwives estimated that $30 \%$ of the women use kgaba in labour.

'When they come to the clinic they are $1 \mathrm{~cm}$ dilated and when you come back after one hour you find she is fully dilated.'

(Interview midwife)

Several midwives had the impression that if the delivery was quicker, the woman also experienced more pain than 'normal'. Women in labour had distinct experiences; some had a very quick labour, while others were disappointed by a long, laborious delivery.

'It helped because most of the time I take 2 days but with kgaba I took only 1 1/2 hours in pain.' (Interview woman)

' It took a long time. That's why I don't believe in TM any longer and I don't want to use them anymore.'

(Woman in focus group)

THs knew only of quick deliveries and many among them expected kgaba to turn a baby who is in a breech position, thus preventing unnecessary operations. 
Afr. J. Trad. CAM (2006) 3 (1): 11 - 22

\section{Perceptions of traditional and western medicine}

The interviews included questions about the strengths and weaknesses of both western and traditional medicine, and what participants thought should be improved across both systems. The findings indicate that THs and women were greatly appreciative of the technical possibilities offered by western medicine. However, western medicine was critiqued due to: lack of massage, the impossibility of having a companion during labour and the judgmental attitude of the staff towards TM. Communication about TM was often one way:

'Here they don't use it because we educate them and tell them not to use it. It is also written on the notice board.'

(Interview midwife)

As a consequence most women are reluctant to admit use of $\mathrm{kgaba}$.

Weaknesses in TM were unclear measurements and preparations, which could cause overdosing and enhance harmful effects.

' I think that they [TM] can be dangerous because they don't have measurements. Maybe when you cook you don't know how much water to use, maybe it is strong you don't know, and again how much to take in a day.'

(Woman in focus group)

In addition, some THs admitted preferring not to be open about their treatment and mixtures and prescribed them disregarding the patients' use of allopathic medicine. This lack of communication about use, dose and ingredients of TM and the parallel use with western medicine hamper evaluation of effects and collection of reliable data. Improvements suggested by all participants included better communication or collaboration on different levels and mutual referrals.

\section{Discussion}

The cultural and traditional belief system of the Tswana is clearly rooted in African tradition and strongly influences the social significance of a disease. Pregnancy and labour are perceived as processes that need follow up and control from western oriented clinics and protection from harm or (evil) spirits by THs. Moreover, THs explain that the ultimate cause of the problem may for example be due to a mother in law who is angry with the woman. Therefore the majority of the women and THs value both medical systems for their distinct qualities.

Where Zulu women focus on the use of TM for cleaning and a quick delivery (Varga and Veale, 1997), emphasis among the Tswana seems to be more on stimulation of prolonged labour or induction when overdue, mainly with the help of crushed ostrich eggshell. Confusion about the expected date of delivery may have a considerable effect on the perceived need to induce labour. The study demonstrated a considerable influence of the older generation. The rural setting of this study may play a role here, as in such contexts the elderly play a critical role in the production and maintenance of traditional knowledge, and grandmothers are closely related to birth and family life (Feierman, 1986).

That churches were found to influence the use of TM negatively, positively or administer herbal decoctions themselves has already been described in 1979 by Conco amongst the southern African Bantu and continues to play a role today. This would imply that medicine from the clinic, 
Afr. J. Trad. CAM (2006) 3 (1): 11 - 22

THs and the church can all be part of the therapeutic arsenal of the Tswana. This may exacerbate adverse effects due to (unknown) contents of decoctions and mixing allopathic and traditional medicine, which hampers adequate assessment and intervention when complications occur.

Observed effects of kgaba on labour outcomes varied in different locations and complications are concentrated in the referral hospital. Unfortunately statistics about the use of TM were lacking and assessment was hampered by the reluctance of the women to admit use to clinic staff. These findings are important for eventual policy changes or health education regarding the use of TM. Several midwives were aware that improvements in health education are needed and many participants proposed closer collaboration between traditional and western medicine. However in Botswana, which is culturally and geographically close to Mogwase district, trained formal health staff often had difficulties in collaborating with THs (Barbee, 1986). Patients value and use both systems, whereas nurses in Botswana, socialised in both health systems, oppose collaboration because of the element of witchcraft they perceive as underpinning TM. Recognition, regulations and more research around the use of TM are urgently needed (HST, 1999). However, progress is hampered by costs, the logistical challenges related to the number and diversity of healers, and the way indigenous knowledge is acknowledged and protected. Perceptions of undermining intellectual property rights may have influenced the reluctance of some THs in this study. Further challenges lie in multiple ways individuals and communities understand the quality of kgaba (hence the many kgabas) and its social and cultural meaning, which is difficult to measure and standardise. The seasonal and regional variation of plants further complicates development of guidelines and influences assessment of efficacy (Hills, 2002).

The qualitative approach and findings from this study provide critical insights into how to address the use of kgaba in late pregnancy and labour. Simply to 'forbid' the use of TM is unlikely to work. Open dialogue around the perceived advantages of TM and their usage is lacking. For the social, spiritual and physical well-being of the Tswana women, further investigations and openness about this remedy is vital. Health promoters may be the important link between the women, and THs and the clinic. Although health promotion as a discipline is not as developed in South Africa as in western countries it has great potential in developing strategies that are grounded in the local cultural and spiritual contexts (Nyamwaya, 2003). Health promoters have the opportunity to build bridges between the two competing health systems. These opportunities are explored by Hill (2003), who suggests that health promoters in Britain view well-being holistically (including the spiritual aspects) as do alternative therapists in complementary or alternative medicine. Health promoters therefore have a potentially important role in creating understanding about culturally sensitive practices, correcting misunderstandings and advancing further research.

\section{Recommendations}

Communication could be improved by including basic principles of traditional medicine in the curriculum of western trained clinic staff, and through additional training on communication skills. Activities of health promotion and education should be based on the needs and knowledge of pregnant women and directed to all decision makers. All parties should stimulate openness about TM and mutual referral and feedback.

The establishment of steering groups in each sub district, with an active role for health promoters, could facilitate collaboration and communication between THs and clinic staff. These groups could explore willingness towards co-operation, assess failures and successes of both health systems and advocate clarity in dosages. 
Afr. J. Trad. CAM (2006) 3 (1): 11 - 22

Further research into the effects of kgaba, which is valuable, accepted and transparent to the communities, is needed. To facilitate this research it is suggested to implement procedures of improved data collection inclinics as well as in the community and incorporate assessment of dose, preparation and benefits of TM. Cultural and traditional Tswana beliefs should be valued and special attention be paid to intellectual property rights of THs.

\section{Conclusion}

This study explored utilisation of traditional medicine in late pregnancy and labour among Tswana women. It aimed to fill a gap in information available on the Tswana population and may contribute to understanding of the therapeutic value of $\mathrm{kgaba}$ and the perceptions guiding its use within this particular socio-cultural context. The challenge of such research is to contribute to positive change whilst not undermining the cultural and social importance that African traditional medicines continue to play in the well being of many African women.

\section{Acknowledgements}

We thank Professor Detlef Prozesky from the Faculty of Family Medicine in Pretoria for his support during the research and all participants for their time and sharing their knowledge and ideas with us. This article was possible due to financial support from the Kenneth Newell Bursary, Liverpool School of Tropical Medicine, United Kingdom.

\section{References}

1. Abrahams, N., Jewkes, R. \& Mvo, Z. (2002). Indigenous healing practices and selfmedication amongst pregnant women in CapeTown South Africa. Afr J Reprod Health 6 (2):79-86.

2. Barbee, E.L. (1986). Biomedical resistance to ethnomedicine in Botswana. Soc Sci Med 22 (1): $75-80$

3. Belew, C. (1999). Herbs and the childbearing woman. Guidelines for midwives. $J$ NurseMidwifery 44 (3): 231-252

4. Bodecker, G. (2001). Lessons on integration from the developing world's experience. $\mathrm{Br}$ Med J 322: 164-167

5. Britten, N. (1995). Qualitative Research: Qualitative interviews in medical research. $\mathrm{Br}$ Med J 311: 251-253

6. Buanews (2003). Institute for traditional medicine. (26-8-03) Available from: www.safrica.info/what_happening/news/traditionalmedicine.htm [Accessed 22 September 2003]

7. Burns, C. (2001). Towards a history of hospitalised childbirth in South Africa. Working paper. Available online at: www.history.und.ac.za/sempapers/burns2001.pdf [Accessed 6 August 2003]

8. Chipfakacha, V. (1994). The role of culture in primary health care. S Afr Med J 84 (12): 860-862. 
Afr. J. Trad. CAM (2006) 3 (1): 11 - 22

9. Conco, W.Z. (1979). The African Bantu traditional practice of medicine: some preliminary observations. In: African therapeutic systems. Ademuwagun, Z.A., Ayoade, J.A.A., Harrison, I.E. \& Warren, D.M. (eds.) Massachusetts: Crossroads Press. pp. 58-80.

10. Drew, A.K. and Myers, S.P. (1997). Safety issues in herbal medicine: implications for the health professions. Med J Aust 166: 538-541

11. Etkin, N. (1988). Ethnopharmacology: biobehavioral approaches in the anthropological study of indigenous medicines. Annu Rev Anthropol 17: 23-42.

12. Feierman, S. (1986). Popular control over the institutions of health, a historical study. In: Last, $\mathrm{M}$ and Chavunduka, G.L. (eds.) The professionalisation of African medicine. Manchester: Manchester University Press. pp. 205-220

13. Freeman, M. and Motsei, M. (1992). Planning health care in South Africa - is there a role for traditional healers? Soc Sci Med 34 (11) 1183-1190.

14. Gonçalves, R. (2001). Assessment of Maternal and Fetal outcomes following Ingestion of Herbal Remedies. AMFIHR Study Protocol 2001. Pretoria. [Unpublished]

15. Good, C.M. (1987). Ethnomedical systems in Africa - Patterns of traditional medicine in rural and urban Kenya. New York: The Guilford Press

16. Gumede, M. (1978). Traditional Zulu practitioners and obstetric medicine. S Afr Med J 53: 823-825.

17. Haram, L. (1991). Tswana medicine in interaction with biomedicine. Soc Sci Med 33 (2): 167-175.

18. Health System Trust (1999). S Afr Health Rev, 1999. Chapter 18. Traditional Healers Available from: http://www.hst.org.za/sahr/99chap18.htm. [Accessed 3 June 2003].

19. Health System Trust (2002). Available from: http://new.hst.org.za/indic/index.php [Accessed 26 September 2003]

20. Hill, F.J. (2003). Complementary and alternative medicine: the next generation of health promotion? Health Promot Int 18 (3): 265-272

21. Hills, S.Y. (2002). Traditional medicine in cancer and AIDS. In: Merriman, A., Opio, D. \& Kebirungi, H. Palliative care training manual for health professionals (1st ed.). Kampala: Hospice Africa Uganda.

22. Hutchings, A. and Terblanche, S.E. (1997).Observations on the use of some known and suspected toxic Liliiflorae in Zulu and Xhosa medicine. S Afr Med J 75: 62-69

23. Jewkes, R., Abrahams, N. and Mvo, Z. (1998a). Study of the health care practices of pregnant women in Cape Town. Report 4. Summary of findings, conclusions and policy actions. Tygerberg: CERCA, Women's health. Medical Research Council.

Available from: www.mrc.ac.za/gender/publications.htm. [Accessed 23 June 2003]

24. Jewkes, R., Abrahams, N. and Mvo, Z. (1998b). Why do nurses abuse patients? Reflections from the South African obstetric services. Soc Sci Med 47 (11): 1781-1795

25. Joubert,P. and Sebata, B. (1982). The role of prospective epidemiology in the establishment of a toxicology service for a developing community. S Afr Med J 62: 853854

26. Kaido, T.L., Veale, D.J.H. and Rama, D.B.K. (1997). Preliminary screening of plants used in South Africa as traditional herbal remedies during pregnancy and labour.

J Ethnopharmacol 55: 185-191

27. Kale, R. (1995). South African's health: traditional healers in South Africa: a parallel health care system. Br Med J 310: 1182-1185

28. Kitzinger, J. (1995). Qualitative research: introducing focus groups. Br Med J 311: 299302. 
Afr. J. Trad. CAM (2006) 3 (1): 11 - 22

29. Mabina, M.H., Pitsoe, S.B. and Moodley, J. (1997). The effect of traditional herbal medicines in pregnancy outcome. The King Edward VIII Hospital experience. S Afr Med J 87 (8): 1008-1010

30. Nyamwaya, D. (2003). Health promotion in Africa: strategies, players, challenges and prospects. Health Promot Int 18 (2): 85-87

31. Ritchie, J. and Lewis, J. (eds.) (2003). Qualitative research practice: A guide for social science students and researchers. London: Sage.

32. Steenkamp, V. (2003). Traditional herbal remedies used by South African women for gynaecological complaints. J Ethnopharmacol 86: 97-108.

33. Thomson, P. (2001). Traditional African Medicine. Genocide and ethnopiracy against the African people. PHARMAPACT. Available from: http://www.gaiaresearch.co.za/ tradmed.pdf. [Accessed 3 June 2003].

34. Ulin, P.R. (1979). The traditional healer of Botswana in a changing society. . In: African therapeutic systems. Ademuwagun, Z.A., Ayoade, J.A.A., Harrison, I.E. \& Warren, D.M. (eds.) Massachusetts: Crossroads Press. pp.243-246

35. Van Wijk,B., Van Oudtshoorn, B. and Gericke, N. (1997). Medicinal plants of South Africa. Pretoria: Briza publications. pp.212-213

36. Varga, C.A and Veale, D.J.H. (1997). Isihlambezo: utilization patterns and potential health effects of pregnancy related traditional herbal medicine. Soc Sci Med 44 (7): 911-924.

37. Veale, D.J.H., Havlik, I., Katsoulis,T., Arangies, N.S., Olive, D.W., Dekker, T., Brookes, K.B. and Doudoukina, O.V. (1998). The pharmacological assessment of herbal oxytocics used in South African traditional medicine. Biomed Environ 2 (2-3): 216-222. Available from: www.lfp.cuni.cz/journals/bioenv/1998/2-3/216-en.html. [Accessed 3 August 2003]

38. Watt, J.M. and Breyer-Brandwijck, M.G. (1968). The medicinal and poisonous plants of Southern and Eastern Africa ( $2^{\text {nd }}$ ed.) London: Academic Press.

39. WHO (2002). Traditional medicine strategy 2002-2005. World Health Organisation, Geneva. pp.1-6. Available from: www.who.int/medicines/organization/trm/orgtrmmain. shtm. [Accessed 16 March 2003]. 